\title{
Market Access through Bound Tariffs
}

\author{
Davide Sala \\ Philipp J.H. Schröder \\ Erdal Yalcin
}
CESIFO WORKING PAPER No. 2858
CATEgOry 8: TRAde Policy
NOVEMBER 2009

Presented At CESifo Venice Summer Institute, July 2009

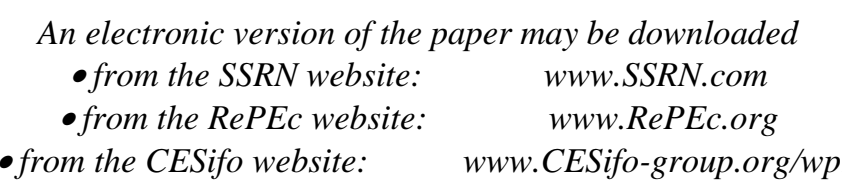




\title{
Market Access through Bound Tariffs
}

\begin{abstract}
WTO negotiations deal predominantly with bound - besides applied - tariff rates. But, how can reductions in tariffs ceilings, i.e. tariff rates that no exporter may ever actually be confronted with, generate market access? The answer to this question relates to the effects of tariff bindings on the risk that exporters face in destination markets. The present paper formalizes the underlying interaction of risk, fixed export costs and firms' market entry decisions based on techniques known from the real options literature; doing so we highlight the important role of bound tariffs at the extensive margin of trade. We find that bound tariffs are more effective with higher risk destination markets, that a large binding overhang may still command substantial market access, and that reductions in bound tariffs generate effective market access even when bound rates are above current and long-term applied rates.
\end{abstract}

JEL Code: F12, F13, F15.

Keywords: bound tariffs, Doha Round, WTO, heterogeneous firms, entry, dynamics, tariff bindings.

Davide Sala
Department of Economics
Aarhus School of Business
Aarhus University
Denmark - 8230 Abyhøj
dsala@asb.dk

\author{
Erdal Yalcin \\ Department of Economics \\ Hohenheim University \\ Box 520 E \\ Germany-70593 Stuttgart \\ e.yalcin@uni-hohenheim.de
}

\author{
Philipp J.H. Schröder \\ Department of Economics \\ Aarhus School of Business \\ Aarhus University \\ Denmark - 8230 Åbyhøj \\ psc@asb.dk
}

November 2009

This working paper is forthcoming in the Scottish Journal of Political Economy (Issue 3, July 2010). We wish to thank Wilhelm Kohler, Simon Evenett and participants at the 11th ETSG annual conference for helpful comments and discussions. We have also benefited from comments of participants on the CESifo Summer Institute Conference "Operating Uncertainty Using Real Options". In particular, we thank Giuseppe Bertola and Michael Funke. Davide Sala and Erdal Yalcin greatly acknowledge CESifo's financial sponsorship. Erdal Yalcin thanks the Aarhus School of Business for hosting him while working on this paper. Philipp Schröder acknowledges financial support from the Danish Social Sciences Research Council (grant no. 275-06-0025) and the Tuborg Foundation. The usual disclaimer applies. 


\section{Introduction}

The lion's share of tariff lines affected by WTO agreements are regulated in terms of bound tariffs, i.e tariff ceilings on applied tariff rates. Bound tariffs are often substantially larger than applied tariff rates. ${ }^{1}$ Today, the unweighed average across 153 current WTO members - of the binding overhang amounts to 23 percentage points and for some WTO members their binding overhang measures more than 100 percentage points. ${ }^{2}$ As a result, WTO negotiations, including membership negotiations, may agree on bound rates that, even after implementing a newly agreed reduction, are above or at the current applied rates, see Evenett (2007) or Bchir et al. (2006).

The question that arises is how such reductions in bound rates, even when ineffective in terms of lowering current applied rates, can generate market access, i.e. the fundamental goal of the WTO. Or put differently, why such a tremendous effort is expanded on WTO negotiations that agree on bound tariffs which may be so substantially higher than applied rates, that hardly any exporter will ever face the agreed bound tariff in reality. ${ }^{3}$ The fundamental driver is that bound tariffs can reduce the risk which exporters face on destination markets. Reduced risk on

1 Various reasons for this phenomenon have been identified, for example dirty tariffication, the value of unused protection, arbitrary ceiling bindings for developing countries, see Walkenhorst and Dihel (2003), Bchir et al. (2006), Anderson and Martin (2005) for detailed discussions.

2 See Bchir et al. (2006) for a detailed discussion and calculations of binding overhang.

${ }^{3}$ See Evenett (2008) for an instructive account of the differences between the economic reasoning and political or legal reasoning in WTO negotiations. In fact, it might be the case that the focus on bound tariffs is justified by the mere fact that they are easier to negotiate compared to applied rates, see also Hoekman and Vines (2007). 
export markets - through bound tariffs and other mechanisms - is known to have substantial effects on trade and country welfare, see for example Van Wincoop (1992), Francois (2001) or Francois and Martin (2004). In an uncertain policy environment with potential changes in the protectionist stance of a given country, tariff bindings reduce the risk that exporters face. Figure 1 illustrates the relation between risk and the size of the binding overhang. As the fundamental arguments concerning bound tariffs and risk would suggest, riskier countries appear to have larger gaps between bound rates and applied tariff rates.

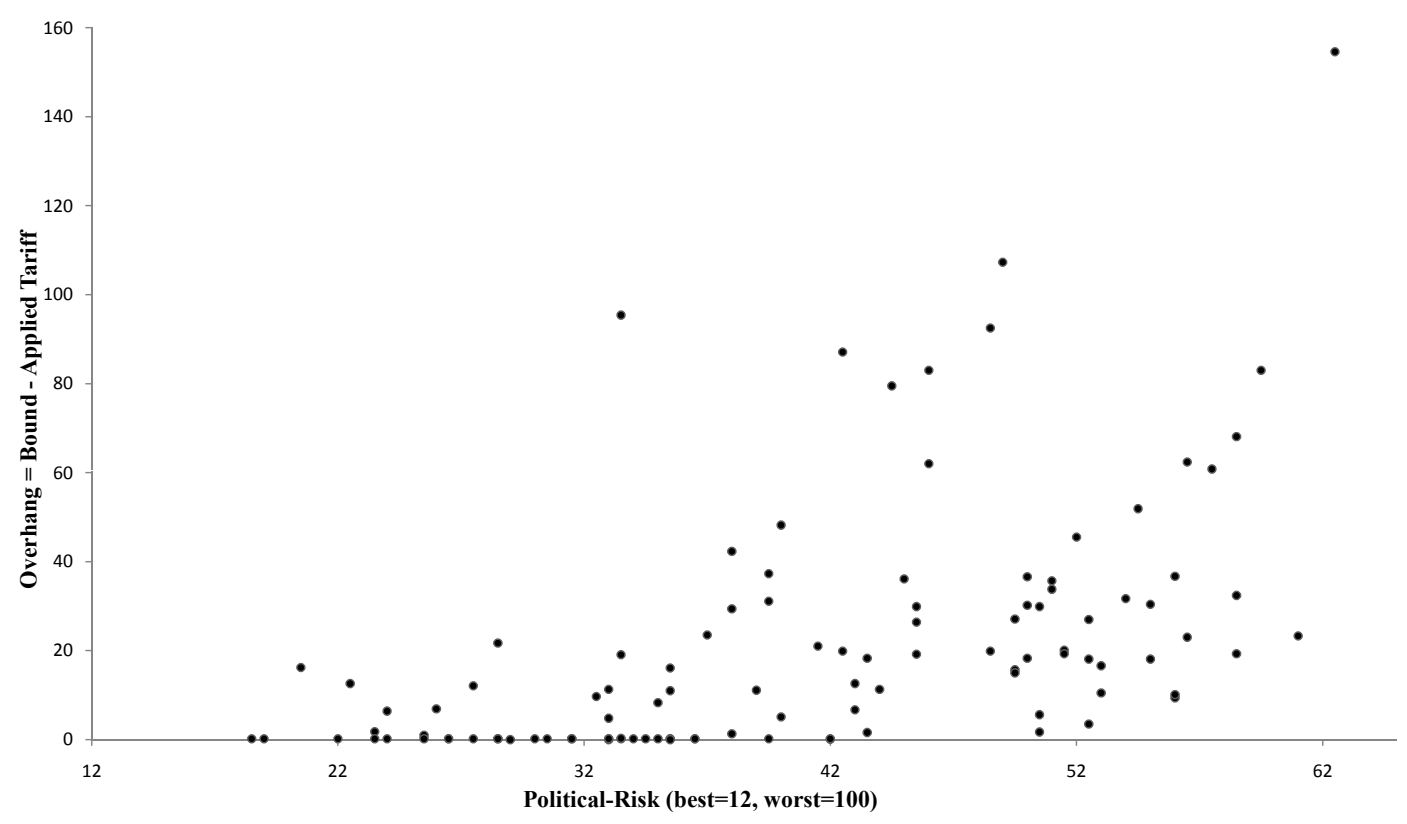

Figure 1: Tariff Overhang.

The binding overhang is here calculated as the simple average of 2007 final bound ad valorem duties of all bound tariff lines minus the simple average of MFN applied ad valorem duties for the same tariff lines (defined at the HS six-digit level). The Appendix lists all countries taken into account. The country-specific political risk measure stems from the PRS-Group. Source: WTO's World Tariff Profiles, 2007.

A one-sided reduction in the volatility of trade policy may in effect appear like 
a reduction in expected future tariffs. However, given that current applied tariffs stay unaltered, such risk reductions can in standard market environments have no direct effect on the current prices that exporters charge on their destination markets. Thus, from the perspective of destination market consumers, reductions in bound tariffs have no effect on prices and hence the demand for and sales volume of a given product, i.e. tariff bindings above applied rates are unable to generate market access via the intensive margin of trade. Accordingly, the effect of bound tariffs on market access must be sought at the extensive margin of trade, i.e. it must stem from the export market entry decision of firms. Here a risk reduction may alter the expected profit flows and thus affect the entry calculation of potential exporters. For example, within the well known Melitz (2003) model, an increase in profits from exports, via a reduction of the average tariff, would clearly affect firm entry via movements of the exporters productivity cut off. Yet, the focus on steady-state equilibria and general equilibrium in this and related mainstream models of international trade makes it difficult to examine the inherently dynamic timing problems of export market entry and bound tariffs.

Against this background, the current paper designs a dynamic, partial equilibrium model of export market entry, dealing with the timing of entry in dependence on risk of the trade policy path in the destination market, reduction in risk via tariff bindings, and firms' fixed export market entry costs. The central driver is that potential exporters to a given destination market can delay market entry and react to the risk reductions generated by bound tariffs. To be explicit, this paper 
does not propose an explanation of why tariff overhang exists. Yet, we do propose a novel perspective on how reductions in the bound rate can affect trade, given that a tariff overhang is present. We thus explain when and why negotiations of bound rates may make good sense in terms of generating market access. In doing so, the paper also offers insights into entirely new channels of trade policy that operate along the time dimension and how such a model allows us to explain hitherto unexplained phenomena, such as the trade effect of reducing bound tariffs in the presence of tariff overhang.

We build our formal model on tools well rehearsed in the real options literature, following Dixit and Pindyck (1994). Moreover, we include the feature of firm heterogeneity, in the tradition of Melitz (2003), to derive results for actual effects on market access, i.e. determining the movements of the export entry productivity cutoff in reaction to changes in the bound tariff rate and other market characteristics. In particular, the model is able to track the rescheduling (in fact a bringing forward) of export market entry triggered by bound tariffs, i.e. the effect that bound rates influence market entry such that some firms access earlier into the export destination, compared to a situation without bindings.

From this model we are able to derive a series of findings concerning the effect of bound tariffs and reductions in bound rates depending on the size of the binding overhang and other market characteristics. We find that bound tariffs are more effective with higher risk destination markets, that a large binding overhang may still command substantial market access, and that reductions in bound tariffs 
generate an effective market access even when bound rates are above current and long-term applied rates.

The paper perhaps closest to the present work is Francois and Martin (2004), who have written the only previous theoretical paper providing a model of the effect of bound tariffs. Yet, their focus is on the cost of protection and not on the effects of bound tariffs on the timing of firms' export market entry decisions, which are at the center of the present analysis. Also, Francois and Martin (2004) operate from a country perspective and provide general equilibrium assessments, while we are able to consider the role of single firms in more detail, following the seminal contribution of Brander and Spencer (1984a,b), yet at the price of staying within a partial equilibrium framework.

The next section develops a basic single firm model of the timing of export market entry building on concepts from the real options theory following Dixit and Pindyck (1994). In Section 3 we extend this framework to include a continuum of heterogeneous firms and present our central results for the effects of bound tariffs on market access. Section 4 presents illustrative simulation results for market access and Section 5 concludes.

\section{The Model}

In this section we model a single firm having to decide upon entry into a new risky foreign market for its product. Competition among firms is not modeled explicitly, 
instead we follow Bertola (1998) and characterize the degree of competition in the potential export market through an iso-elastic demand function given by:

$$
p=Z y^{\mu-1}, \quad 0 \leq \mu \leq 1
$$

where $p$ represents the price of a firm's output $y$ offered in the destination country. $\mu$ is indexing the market power of the firm, as for $\mu=1$ the demand curve is horizontal (i.e. the market is perfectly competitive), whereas for $\mu \neq 1$ the demand function is negatively sloped. $Z$ is a shift factor, including for instance factors like the income or the size of a country.

An ad valorem tariff $\tau$ is levied on the firm 's product, introducing a discrepancy between $p^{C}$, the price paid by a foreign consumer and $p^{F}$, the price received by the firm, with

$$
p^{F}=\frac{p^{C}}{(1+\tau)}, \quad \tau \geq 0
$$

The firm maximizes the per-period cash flow (the time subscript $t$ is omitted to save notation as all variables are at $t$ ),

$$
\begin{aligned}
& \pi=\max _{y \geq 0} p^{F} y-c(w, y) \\
& \text { s.t. } \quad p^{C}=Z y^{\mu-1} \quad \text { and } \quad p^{F}=\frac{p^{C}}{(1+\tau)}, \quad \tau \geq 0
\end{aligned}
$$

where $c(w, y)$ is a general cost function of a bundle of inputs describing the technology of the firm. For illustrative purposes and without loss of generality, we specify 
the cost function - similarly to Dixit and Pindyck (1994) - to be: ${ }^{4}$

$$
c(w, y)=\frac{w y^{\frac{1}{\theta}}}{\phi}, \quad \theta \leq 1
$$

where $w$ is the wage prevailing on the labour market, $\phi$ is the labour productivity and $\theta \leq 1$ indicates diminishing marginal return in the factor labour. Hence, the maximum per-period profit flow of the firm is,

$$
\pi(\tau)=B\left(\frac{Z}{1+\tau}\right)^{k}\left(\frac{\phi}{w}\right)^{\mu \theta k}
$$

with $k=\frac{1}{1-\mu \theta}$ and $B=(1-\mu \theta)(\mu \theta)^{\mu \theta k}$. Note that it depends inversely on the advalorem tariff, $\partial \pi / \partial \tau \leq 0$, so that the trade policy in place in the foreign market will play an important role in the entry decision of the firm.

\subsection{Trade Policy}

The firm faces uncertainty concerning the trade policy regime on the foreign market. The foreign government can unexpectedly resort to a higher tariff rate than the one currently in force. Several reasons have been put forward in the literature for such a regime switch: contingent protection, political risk, lack of international credibility, just to name a few. The well established argument of "time inconsis-

4 This cost function corresponds to the technology $y=(\phi l)^{\theta}, \quad \theta \leq 1$. See also Dixit and Pindyck (1994). 
tency" of trade policy is modeled here in the most simple form, assuming that the applied ad-valorem rate can be either the current level $\left(\tau_{l}\right)$ or higher $\left(\tau_{g}\right) .{ }^{5}$ Yet, where applicable, the new rate cannot exceed the bound tariff, $\tau_{\beta}$, the highest legal rate in the WTO tariff-ceiling system. From the perspective of the firm, this "trade policy" shock is distributed i.i.d. Bernoulli and has probability density function:

$$
P(\tau)= \begin{cases}1-\gamma & \text { for } \tau(t)=\tau_{l}(t) \\ \gamma & \text { for } \tau(t)=\tau_{h}(t)\end{cases}
$$

where $\tau_{h}(t)=\min \left[\tau_{g}(t), \tau_{\beta}(t)\right]$, and the expected tariff is

$$
E(\tau(t))=(1-\gamma) \tau_{l}(t)+\gamma \tau_{h}(t)
$$

To highlight that our results depend exclusively on the eventuality that a government may resort in the future to higher tariff rates, even though - in practice may never do so, we abstain from any other source of uncertainty. ${ }^{6}$ To stretch this point, we assume that the firm not only knows the current rate, but also the whole future tariff evolution. Tariff rates at any point in time are $^{7}$

$$
\begin{aligned}
& \tau_{j}(t)=b_{j} e^{-\alpha_{j} t}, \quad \alpha_{j} \geq 0, \quad j=l, g \\
& \tau_{\beta}(t)=b_{\beta}
\end{aligned}
$$

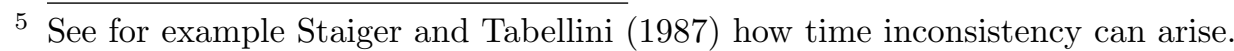

6 Uncertainty on $\tau_{g}$ would not change any of the results.

7 Note that (8) is the solution to an homogenous differential equation on $\tau_{s}(t), s=l, g$. 
with $\alpha_{l} \geq \alpha_{g}$, and $b_{j}$ indicating the rate in the initial period (so that, $b_{j}=1$ would indicate an initial ad-valorem tariff of 100\%). Note that both the high and low tariff paths involve some degree of tariff liberalization, but $\tau_{g}(t)$ indicates the most protectionist path. The case of $\tau_{l}$ and $\tau_{g}$ being respectively a low and a high flat tariff rate is a special case with $\alpha_{l}=0$ and $\alpha_{g}=0$. Instead, reflecting WTO regulations, the bound tariff is modeled as a flat ceiling rate.

\section{$2.2 \quad$ Firm Entry}

The focus in our model is on the time of entry into the market and how trade policy can shape such a choice. Consistently with overwhelming recent evidence - to enter a foreign market the firm must occur a sizeable upfront fixed cost $F_{e}{ }^{8}$ Entry is irreversible, but the decision to enter can be postponed, as in McDonald and Siegel (1986) and Pindyck (1991). ${ }^{9}$ Timing of entry will strategically reflect the forward-looking behaviour of the firm which correctly anticipates that the perperiod cash flow grows over time as the tariff rate decays at rate $\alpha_{j}$ each year while $F_{e}$ is unchanged and incurred only in the investment period. At the base of the firm's trade-off, there is a no-arbitrage opportunity between the value of the investment in the foreign market and the opportunity cost of non-pursuing alternative investments. Therefore, after a waiting time of $T$ periods, entry can

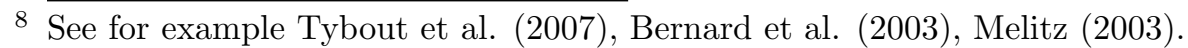

9 The framework can be extended to reversible entry, but our choice reflects our interest for analyzing the role trade policy plays on market access. 
only be optimal provided the value of the firm $V$ exceeds the fixed cost of entry,

$$
V\left(\tau, T, t_{0}\right)=\int_{t_{0}+\left(T-t_{0}\right)}^{\infty}\left[(1-\gamma) \pi\left(\tau_{l}(s)\right)+\gamma\left[\pi\left(\tau_{h}(s)\right)\right] e^{-r\left(s-t_{0}\right)} d s \geq F_{e} e^{-r\left(T-t_{0}\right)}\right.
$$

Note that if $T=t_{0}$ (i.e. entry occurs in the initial period), equation (10) is the Marshallian entry condition when firms have no option to postpone entry. It simply implies entry if the expected present discounted value of the stream of profits at $t_{0}$ exceeds the fixed cost. However, if entry can be delayed, the optimal waiting time can be determined by:

$$
\max _{T} \quad W(T) \equiv V\left(\tau, T, t_{0}\right)-F_{e} e^{-r\left(T-t_{0}\right)}
$$

yielding the following FOC which makes use of the Leibnitz rule:

$$
\frac{\partial W(T)}{\partial T}=-\left[(1-\gamma) \pi\left(\tau_{l}(T)\right)+\gamma \pi\left(\tau_{h}(T)\right)\right] e^{-r\left(T-t_{0}\right)}+F_{e} e^{-r\left(T-t_{0}\right)} r=0 .
$$

Rearranging it, we obtain the Jorgensonian rule, equating the per-period profit flow to the user cost of capital, ${ }^{10}$

$$
E \pi(T) \equiv\left[(1-\gamma) \pi\left(\tau_{l}(T)\right)+\gamma \pi\left(\tau_{h}(T)\right)\right]=F_{e} r
$$

\footnotetext{
${ }^{10}$ See Jorgenson (1963).
} 
which best balances the trade-off at the heart of the Real Option Approach between the benefit and the cost of further waiting. Only when the two sides are equalized, entry can be optimal; else, either earlier entry or further waiting would be preferable. It is important to note that such a trade-off depends exclusively on $F_{e}$ and $\alpha_{j}$, regardless of uncertainty.

However, uncertainty is crucial for trade policy to affect the entry decision of a firm: in absence of uncertainty, $\left(\gamma=0\right.$ or $\left.\tau_{h}(t)=\tau_{l}(t)\right)$, the optimal waiting time in (12) responds only to current tariff rates, while with uncertainty it also responds to $\gamma$ and $\tau_{h}$ even if current rates are unchanged. The reason is that the expected tariff increases with $\gamma$ and $\tau_{h}$, reducing the attractiveness of the market in terms of expected return (i.e. cash flow).

The risk faced by an exporter has two sources: the likelihood that a tariff regime switch occurs, as measured by $\gamma$, and the size of the jump, namely the difference between the high and low rates, $\tau_{g}(t)-\tau_{l}(t)$. To see this, from a Bernoulli distribution, the variance of the tariff rate is,

$$
\sigma(\tau)=(1-\gamma) \gamma\left(\tau_{h}-\tau_{l}\right)^{2}
$$

which is increasing in $\tau_{h}-\tau_{l}$, but non-monotonic with an inverted U-shape in $\gamma^{11}$ Such a risk, where a bound tariff is applicable, is limited by the overhang, the difference between the bound rate and the applied rate, i.e. $\tau_{\beta}-\tau_{l}$. $11 \frac{\overline{\partial \sigma(\tau)}}{\partial \gamma}=\left(\tau_{h}-\tau_{l}\right)^{2}(1-2 \gamma)$, which is increasing for $\gamma \leq 1 / 2$. 
We solve for the optimal entry time inserting (5) in the FOC (12) and obtain an implicit equation for the entry time $t_{0}+T$,

$$
B Z^{k}\left(\frac{\phi}{w}\right)^{\mu \theta k}\left[(1-\gamma)\left(1+\tau_{l}(T)\right)^{-k}+\gamma\left(1+\tau_{h}(T)\right)^{-k}\right]=r F_{e}
$$

For convenience, we define $t_{0}=0$ so that the entry time is equal to the waiting time $T$.

The implications for the optimal entry time $T$ are best explained with the help of Figure 2. The $\pi\left(\tau_{l}(T)\right)$ curve represents the highest possible per-period cash flow in the low-tariff scenario, while the $\pi\left(\tau_{g}(T)\right)$ curve represents the highest possible cash flow in the high-tariff scenario. Note that the firm's periodical cash flow is increasing with time along these curves because of the declining tariff rate. The vertical distance of these two curves represents the maximum swing of the cash flow, what we label the "risk band", and it depends exclusively on the $\tau_{g}$-type of risk. The LHS of (14) - the expected periodical cash flow between the two tariff scenarios - is depicted as the S-shape dashed curve denoted by $E \pi(T)$. By definition, it lies necessarily within the risk band and its position depends on both types of risk. At the intersection with the flat curve $r F_{e}$, the optimal entry time, $T_{\gamma}$, is determined. Clearly, the optimal entry time will depend on firm and market characteristics; it will be earlier for more productive firms (higher $\phi$ ), larger markets (higher $Z$ ), or lower export market entry costs $\left(F_{e}\right)$, while for riskier markets (higher $\gamma$ or $\tau_{g}$ ) timing of entry is stretched longer. 


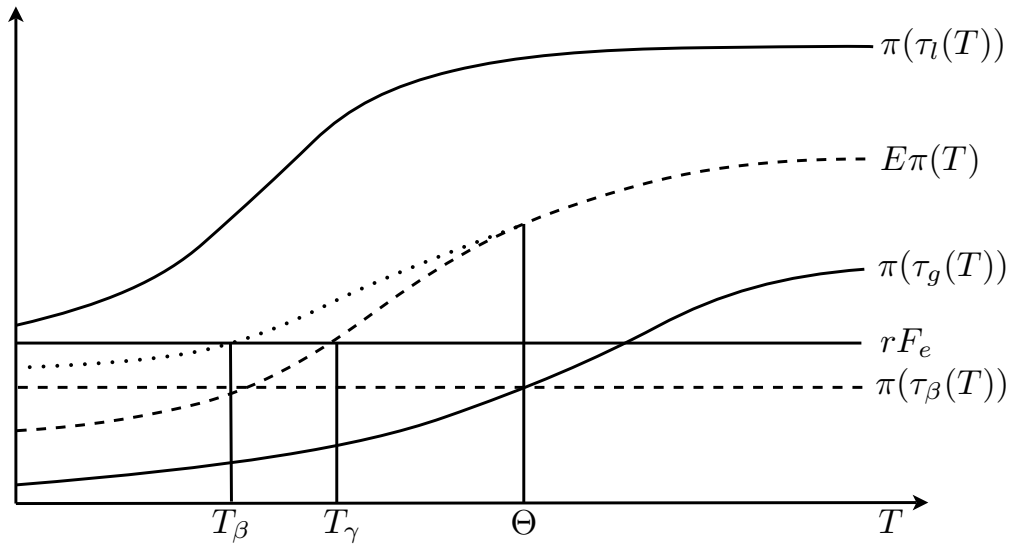

Figure 2: Bound tariff and the Timing of Market Entry

$\pi\left(\tau_{l}(T)\right)$ and $\pi\left(\tau_{g}(T)\right)$ are, respectively, the firm's per-period cash flow in the low and in the high tariff scenarios. Entry occurs at $T_{\gamma}$, when the firm's expected per-period cash flow $E \pi(T)$ is equal to the per-period entry cost $r F_{e}$. In a tariff ceiling system, entry can be anticipated at $T_{\beta}$.

\subsection{Trade Policy and Timing of Entry}

Let us turn to the role of the bound tariff in reducing the firm's risk and therefore the timing of entry. In presence of a bound tariff, $\tau_{\beta}=b_{\beta}$ is the highest possible applied tariff a government could resort to. Such a tariff ceiling translates into a floor for the per-period cash flow, so that the highest possible cash flow in the protectionist tariff scenario is the maximum between the $\pi\left(\tau_{g}(T)\right.$ curve and the $\pi\left(\tau_{\beta}(T)\right.$ dashed flat curve. For time $T>\Theta$, the bound tariff is above $\tau_{g}$ and loses its effectiveness to possibly bound the risk of a policy reversion toward a more protectionist stance. Therefore, it produces no effect on the timing of entry. For $T_{\gamma}<\Theta$, the bound tariff effectively limits the possible tariff increment, inducing 
the firm to anticipate entry at $T_{\beta}$. Indeed, the cash flow floor raises the expected per-period cash flow, as indicated by the upward shift of the $E \pi(T)$ curve.

Finally, note that in our graph a further reduction of the bound rate induces even an earlier entry by the firm.

These findings can be summarized by

Proposition 1. A flat bound tariff $\tau_{\beta}=b_{\beta}$ implies (i) $T_{\beta}=T_{\gamma}$, if $\tau_{\beta} \geq \tau_{g} \forall T$ (ii) $T_{\beta}=T_{\gamma}$, if $\tau_{\beta} \leq \tau_{g}$ and $T_{\gamma} \geq \Theta \forall T$ (iii) $T_{\beta}<T_{\gamma}$, if $\tau_{l} \leq \tau_{\beta} \leq \tau_{g}$ and $T_{\gamma} \leq \Theta \forall T$ (iv) $T_{\beta}<T_{\gamma}$, if $\tau_{\beta} \leq \tau_{l} \forall T$.

They equally apply to two different situations. They are relevant for countries adhering to WTO and having to transit from a discretionary trade policy regime to a tariff ceiling system, as well as to WTO member countries engaged into negotiations of bound tariffs. In both situations, the introduction or a negotiated reduction of a bound tariff $\tau_{\beta}$, which is not affecting the applied tariff directly, will generate market access even if $\tau_{l}$ is well below the bound. This appears to be in contrast to discussions taking place at WTO negotiations, where parties frequently deduce that only cuts in bound rates below current applied tariff rates can generate market access, see Evenett (2007) for an account of current negotiations.

However, the effectiveness of a bound tariff is limited and the effective region depends - in our framework - on the relative position of $T_{\beta}$ or $T_{\gamma}$ with $\Theta$. In particular, we highlight how two factors, namely the design of the bound tariff and 
the width of the risk band, influence this region. First, if the bound tariff was engineered as a "crawling peg", decaying at a positive rate instead of being just a ceiling tariff, its effectiveness would not be time-restricted. This highlights why negotiations about reductions in bound rates might in fact be driven by reductions in applied rates and not the other way around. Second, to generate any market access the bound tariff has to be below the highest possible applied tariff rate and, therefore, the larger the risk band, the greater the likelihood that a particular bound tariff level results effective. This implies an important relation between each type of risk and the highest bound tariff proven to be effective. As it can be noted in Figure 2, such a bound rate is the one for which the $\pi\left(\tau_{\beta}\right)$ curve intersects the $\pi\left(\tau_{g}\right)$ curve at $T_{\gamma}$. It follows, that the higher $\gamma$, the more to the right will be $T_{\gamma}$, implying that a lower bound tariff level is necessary to result effective. For the $\tau_{g}$-type risk, instead, the relation is ambigous, as a higher $\tau_{g}$ shifts down both the $E \pi(T)$ curve and $\pi\left(\tau_{g}\right)$ curve. Therefore, a lot of water in the tariff does not necessarily mean ineffective bound.

\section{Implications for Market Access}

While the above framework has derived results in terms of the decision of a single firm, we are now able to move towards the implications for actual market access. Consider a continuum of potential entries into the market in question, this may be already active exporters - exporting into alternative destination markets - or 
pure domestic firms from various foreign countries. Furthermore, assume that all the potential entries face an identical fixed export market access cost, $F_{e}$, but have different firm-specific productivity $\phi$, as in Melitz (2003). For each point in time a critical $\phi^{*}(t)$ exists such that firms with a lower productivity will not have accessed the market, while firms with higher productivity will have entered. Accordingly, changes in $\phi^{*}(t)$ are a measure of market access.

Totally differentiating both sides of equation (14) with respect to $b_{\beta}, \phi, F_{e}$ and $Z$ gives the change in the optimal entry time for a small perturbation of the constellation of parameters:

$$
\begin{aligned}
(1-\gamma) k \alpha_{l} \tau_{l}(T)\left(1+\tau_{l}(T)\right)^{-(k+1)} d T= & \gamma k\left(1+b_{\beta}\right)^{-(k+1)} d b_{\beta} \\
& -\Gamma Z^{-k} F_{e} \mu \theta k \phi^{-(\mu \theta k+1)} d \phi \\
& +\Gamma Z^{-k} \phi^{-\mu \theta k} d F_{e} \\
& -k \Gamma F_{e} \phi^{-\mu \theta k} Z^{-(k+1)} d Z
\end{aligned}
$$

which is true for $T<\Theta$, implying $d T / d \phi \leq 0$ for $d b_{\beta}=d F_{e}=d Z=0$ and which in Figure 3 defines a negative sloped iso-bound tariff curve in the $(T, \phi)$ space. We depict this curve dashed because we only know its slope qualitatively, but not its exact shape. Nevertheless, this suffices for our purposes. The outer right dashed level curve $T_{\gamma}(\phi)$ depicts the market entry time of firms with different productivity levels for a specific bound tariff $b_{\beta}$ higher than the highest possible applied tariff 


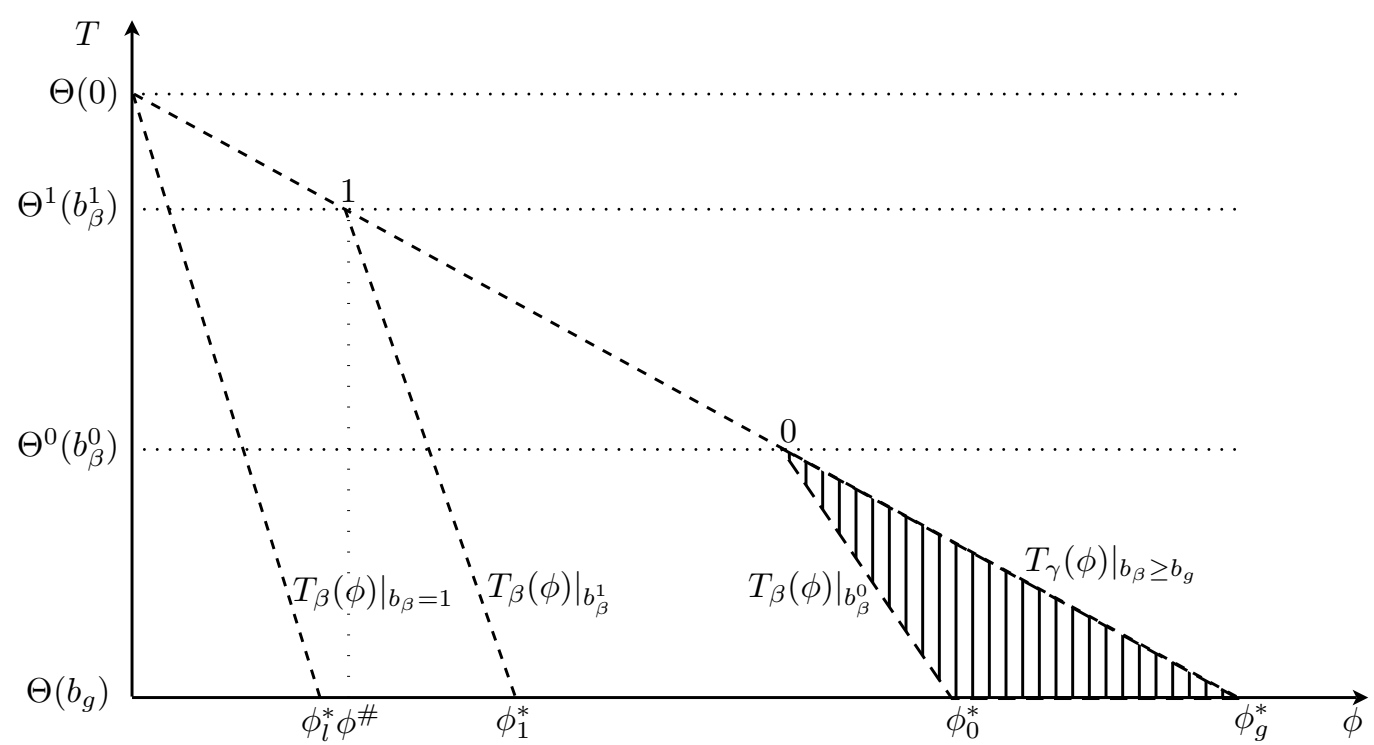

Figure 3: Market Access through Bound Tariff.

The hatched area indicates the additional market access achieved through a reduction in the bound tariff. Firms with a productivity between $\phi_{g}^{*}$ and $\phi_{0}^{*}$ enter the market earlier.

$\tau_{g}$ at any time. Therefore, all firms exhibiting a productivity level higher than $\phi_{g}^{*}$ enter the destination market immediately $(T=0)$, whereas companies with lower productivity rather delay entry. As derived above, the effectiveness of a bound tariff is confined to a time range where the optimal market entry time $T_{\gamma}$ is smaller than $\Theta$. For a bound tariff, e.g. $b_{\beta}^{0}<b_{h}$, its effectiveness is constrained to $\Theta^{0}\left(b_{\beta}^{0}\right)$, depicted as a horizontal dotted line. Only firms with an optimal market entry time $T_{\gamma}<\Theta^{0}\left(b_{\beta}^{0}\right)$ benefit from a lower expected tariff in the form of earlier market entry time $\left.T_{\beta}(\phi)\right|_{b_{\beta}^{0}}$. As a result, the new iso-bound tariff curve for a given $b_{\beta}^{0}$ is kinked at the point indicated by 0 . The hatched area between the new and the old isobound tariff curve defines the productivity range of firms which anticipate market entry. The new productivity cutoff which determines the instantaneous market 
entry $(T=0)$ is $\phi_{0}^{*}$. It is worth noting that all firms with a productivity level between $\phi_{0}^{*}$ and $\phi_{h}^{*}$ would have delayed their market entry, had the bound tariff not been lowered; therefore, the difference $\phi_{0}^{*} \phi_{h}^{*}$ corresponds to the new market access due to a bound tariff $b_{\beta}^{0}$. Figure 3 also shows the effect of a further reduction of the bound tariff e.g. to $b_{\beta}^{1}$ (ceteris paribus). This reduction results in a higher effectiveness range $\Theta^{1}\left(b_{\beta}^{1}\right)>\Theta^{0}\left(b_{\beta}^{0}\right)$ depicted by the central dotted line and in a new iso-bound tariff curve $\left.T_{\beta}(\phi)\right|_{b_{\beta}^{1}}$ which is kinked at point 1.

Implicitly, there are three groups of firms which are differently affected by the reduced bound tariff. All firms with a productivity level between $\phi_{1}^{*}$ and $\phi_{0}^{*}$ bring their entry decision forward to such an extent that they enter today (new market access). The second group of firms exhibiting a productivity level between $\phi^{\#}$ and $\phi_{1}^{*}$ are also positively influenced by the bound tariff reduction, forestalling their future entry. The last group of firms with a productivity lower than $\phi^{\#}$ are unaffected, as their market entry time $T_{\gamma}$ falls out of the responsive range delimited by $\Theta^{1}\left(b_{\beta}^{1}\right)$. The iso-bound tariff curve for productivity levels smaller than $\phi^{\#}$ coincides indeed with the level curve of a boundless situation $\left(\left.T_{\gamma}\right|_{b_{\beta} \geq b_{h}}\right)$.

It is worth noting that the market access generated through a reduction of a bound tariff is at the extensive margin of trade and further reductions in the bound rate can trigger additional access, also because they enlarge the effectiveness region. However, the effect a change in the bound rate can induce is clearly limited. On the one hand, it is limited by a natural bound which is free trade, so that the horizontal intercept of the iso-curve defined by $\left.T_{\beta}(\phi)\right|_{b_{\beta}=0}$ gives the ultimate $\phi_{l}^{*}$, 
the lowest productive producer that will ever find it worthwhile to enter the market today. On the other hand, no bound tariff higher than the worst tariff rate can be effective, defining $\phi_{h}^{*}$, the highest possible productivity threshold triggering entry without delay. It follows, depending on the level of the bound tariff, that the lowest productive exporter will range between $\phi_{l}^{*}$ and $\phi_{h}^{*}$.

Finally, the same exercise could be performed for $F_{e}$, i.e. heterogeneous fixed export costs across firms, or market size $Z$, and cutoffs for market entry in terms of fixed costs and market size can be analogously derived.

To put our results into perspective, let us consider Figure 1 again, where the political risk on the horizontal axes can be interpreted as the $\gamma$-type risk in our model and the overhang as the ceiled risk band ( $\tau_{g}$-type risk). Riskier countries - which exhibit also significantly higher overhangs - can to some extent influence market access through bound tariff negotiations, but the range of market access generated ultimately depends on the effectiveness region, indicated by $\Theta$ in our model. In contrast, in developed countries - where low overhangs prevail - the importance of bound tariffs as a market access control can play only a minor or negligible role. The next section proposes a theoretical simulation to quantify market access for different risk profiles as well as different types of economies. 


\section{Market Access: A Quantitative Assessment}

The previous section has shown how reduction in the bound rate can induce market access at the extensive margin of trade, but it has also highlighted that the scope as well as the effectiveness of such a policy depends crucially on the specific situation in a given country. In this section we provide numerical simulations that illustrate how market access responds to cuts in bound rates that remain above applied rates, for different risk profiles and different type of markets. Throughout the section we consider the policy experiment of a ten per cent cut in the bound tariff rate. First, we focus on the market access this policy generates in economies characterized by different levels and types of risk. In particular, we distinguish the $\gamma$-type risk and the $\tau_{g}$-type risk represented in the model. This corresponds to separate countries with similar overhang, but different political risk from countries with alike political risk, but different worst case tariff level. Second, we explore how the result of this policy weighs upon market specificities as captured by the degree of competition, the fixed cost of entry, and the income of a country.

Market access is quantified as follows. We assume that all potential entrants can be ranked according to their firm-specific productivity, as in Montagna (2001). Let $D(\phi)$ be the density of the productivity distribution at $T=0$, and $\phi_{0}^{*}$ and $\phi_{1}^{*}$ be the entry productivity cutoff at $T=0$, respectively, before and after the policy 
experiment. This defines market access as:

$$
\operatorname{Market}_{\operatorname{Access}_{\mid T=0}}=\frac{D\left(\phi_{0}^{*}\right)-D\left(\phi_{1}^{*}\right)}{1-D\left(\phi_{0}^{*}\right)}
$$

In particular, we follow the recent trade literature and assume that $D(\phi)$ is a generalized Pareto:

$$
D(\phi)=1-\left(1+\frac{a(\phi-\chi)}{\sigma_{\phi}}\right)^{-\frac{1}{a}} \phi \geq \chi, a>0, \sigma_{\phi}>0, \chi \in \mathbb{R}
$$

If the location parameter $\chi$ and the scale parameter $\sigma_{\phi}$ are alike, the generalized Pareto is equivalent to a Pareto distribution, provided the shape parameter $a$ is positive. Henceforth, we further assume that $\chi=\sigma_{\phi}{ }^{12}$ The higher $a$, the thicker the tail of the Pareto distribution.

For any given level of risk, set $T=0$ in (14) to solve it for the critical entry productivity threshold $\phi_{0}^{*}$. $\phi_{1}^{*}$ - the solution obtained after a cut of ten per cent in the bound rate - is analogously obtained. The value for all the parameters are listed in Table 1 . We shall refer to these values as our benchmark simulation. In the choice of the parameter values we follow Dixit and Pindyck (1994). ${ }^{13}$

First, we fix $\tau_{g}$ and iterate this exercise for the whole space spanned by $\gamma$-type

${ }^{12}$ See Melitz and Ottaviano (2005) as an example using the Pareto distribution. The choice of implementing the Pareto as a special case of the Generalized Pareto is closely related to the software used for the simulation.

${ }^{13}$ A detailed discussion on reasonable parameter values can be found in Dixit and Pindyck (1994, Chapter 7). 


\begin{tabular}{|c|c|c|}
\hline \multicolumn{3}{|l|}{ Parameter Values } \\
\hline & Abbreviation & Numerical Value \\
\hline Discount Rate & $r$ & 0.04 \\
\hline Firms' Entry Fixed Costs & $F_{e}$ & 50 \\
\hline Production Function Parameter & $\theta$ & 0.8 \\
\hline Inverse Mark-up & $\mu$ & 0.7 \\
\hline Market Size & $Z$ & 2 \\
\hline Wages & $w$ & 1 \\
\hline Decaying Rate of Low Tariff & $\alpha_{l}$ & 0.01 \\
\hline Decaying Rate of High Tariff & $\alpha_{h}$ & 0.04 \\
\hline Low Tariff Level & $b_{l}$ & $5 \%$ \\
\hline High Tariff Level & $b_{h}$ & $230 \%$ \\
\hline Shape Parameter of Pareto Distribution & $\mathrm{a}$ & 0.25 \\
\hline Scale Parameter of Pareto Distribution & $\sigma_{\phi}$ & 1 \\
\hline Location Parameter of Pareto Distribution & $\chi$ & 1 \\
\hline \multicolumn{3}{|l|}{ a) Gamma Simulation: } \\
\hline Country Risk & $\gamma$ & $(0,1)$ \\
\hline \multicolumn{3}{|l|}{ b) High Tariff Simulation: } \\
\hline Country-Specific Risk & $\gamma$ & 0.7 \\
\hline High Tariff & $\tau_{h}$ & $(5 \%, 230 \%)$ \\
\hline
\end{tabular}

Table 1: Parameter Values for the Simulations

risk and the overhang $\tau_{\beta}-\tau_{l}$ : we obtain the market access generated by a ten per cent reduction of a bound rate for each combination of risk and overhang. We present our results in Figure 4 by means of level curves. Each level curve depicts all the combinations of risk and overhang yielding the same market access as a consequence of a ten per cent reduction in the bound rate. For instance, if a country is exactly located on a level curve denoted by 6 , it will experience a six per cent additional market access after lowering the bound rate of ten per cent. If 100 foreign firms were initially present on the market, 6 additional firms are expected to enter the market after the bound rate is cut.

The graph shows that countries with a relatively higher risk are the ones that benefit most from a cut in the bound tariff. This reflects that the two types of risk are reinforcing each other: inspecting (13), risk is low for either a low overhang 


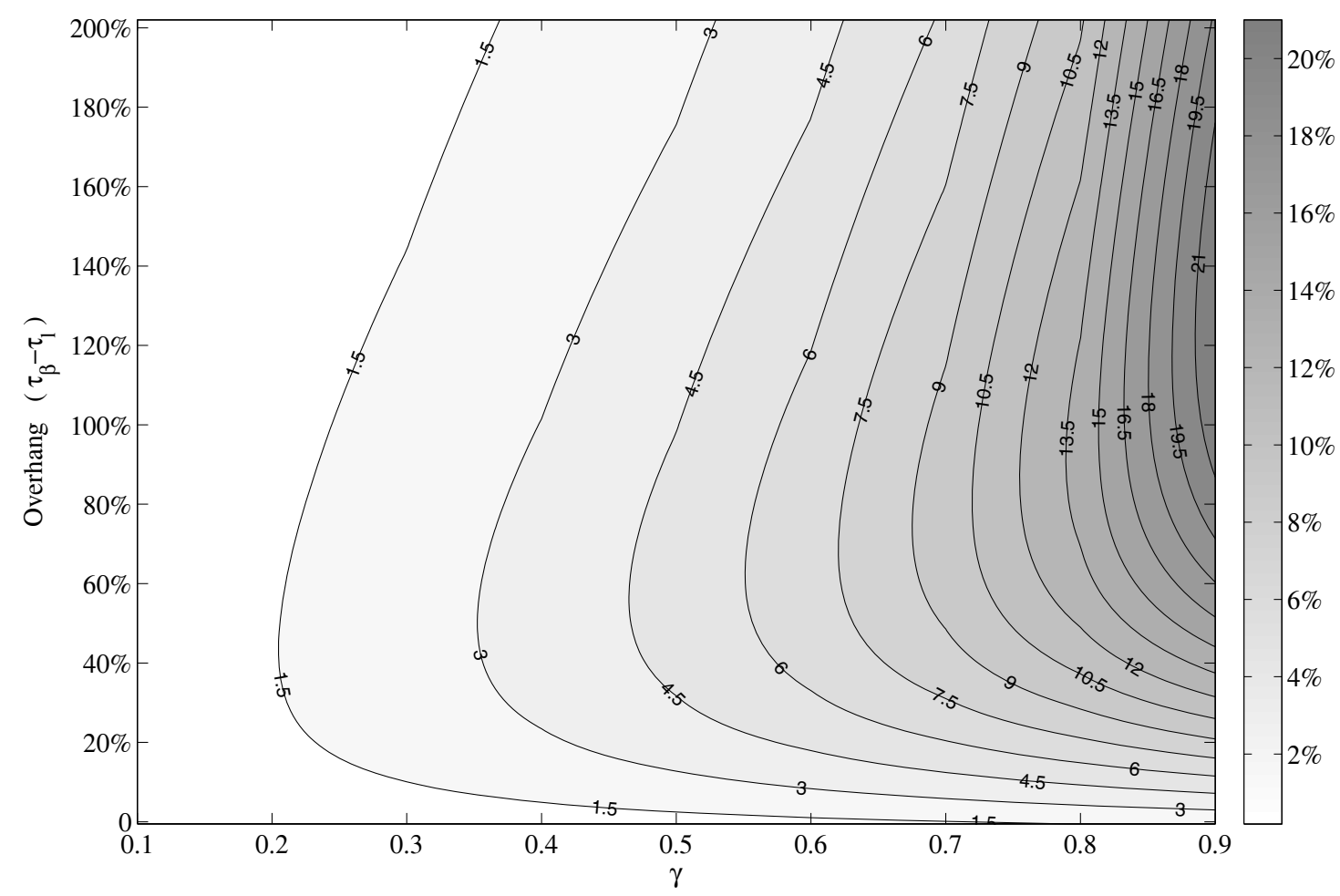

Figure 4: Level Curves for Market Access Induced by Bound Tariff Reduction.

Each level curve represents combinations of different $\gamma$-type risk and overhang rates which lead to the same additional market access after a reduction of $10 \%$ in the bound rate. The underlying parameter values for the simulation can be found in table 1.

or a low probability of tariff regime shift, or in the North-West, South-West and South-East regions of the graph. In the East region, risk is high and the bound tariff is a valuable device to limit such risk. Therefore, this is also the region where a reduction of ten per cent in the bound rate is most effective to foster further entry. In contrast, in the North-West, South-West and South-East corners of the graph, there is hardly any risk. Accordingly, the value of insurance - given by the cut in bound rates - is minor. Here, other policies - different from bound rate negotiations - must be evoked to promote market access: for example, cuts in applied tariffs or reductions in entry barriers. 


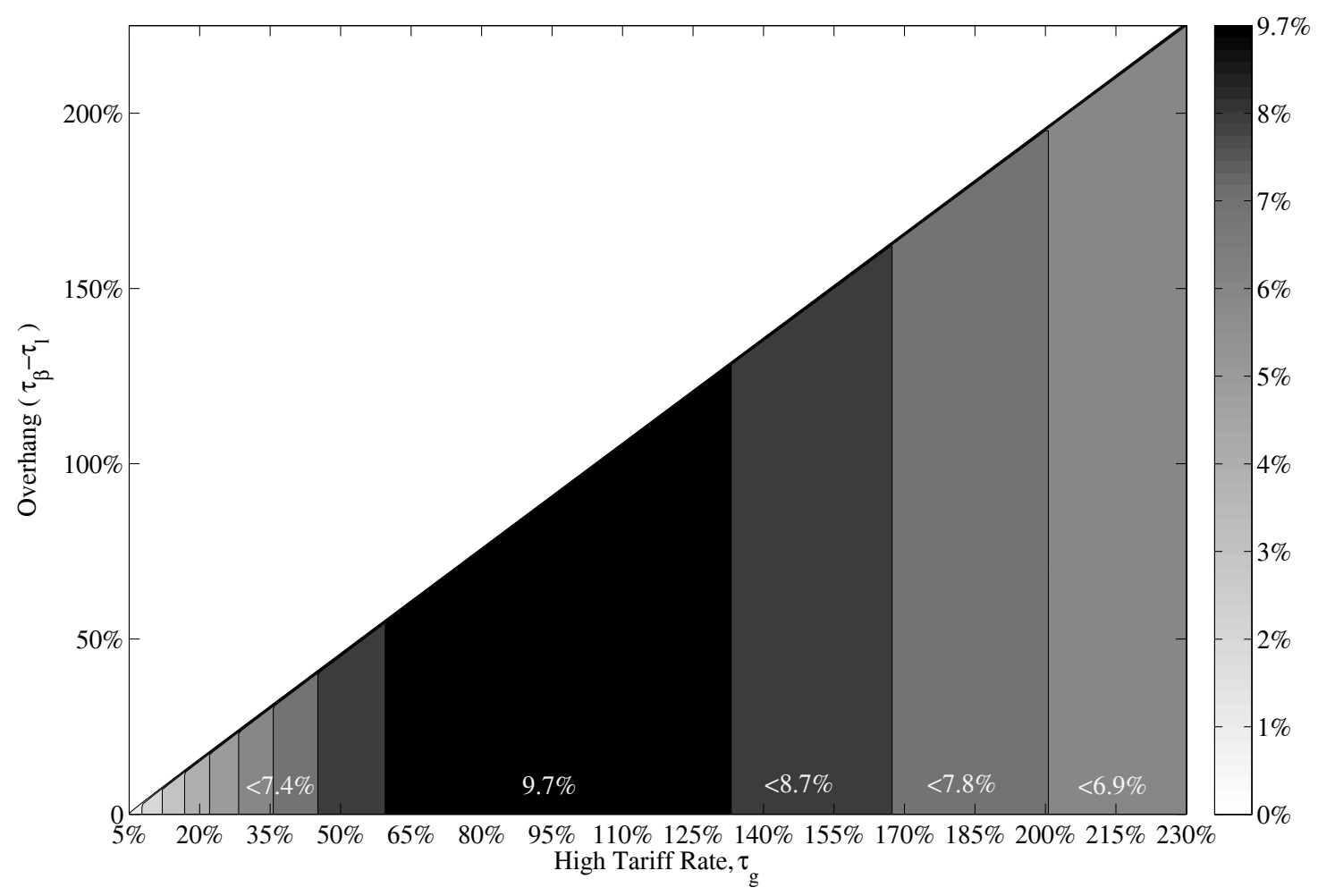

Figure 5: Level Curves for Market Access at Different High Tariff Rates.

Each level curve represents combinations of different $\tau_{g}$-type risk and overhang rates which lead to the same additional market access after a reduction of $10 \%$ in the bound rate. The underlying parameter values for the simulation can be found in table 1 .

Second, we fix $\gamma$ and perform the same exercise for the space spanned by the $\tau_{g}$-type risk and the overhang $\tau_{\beta}-\tau_{l}$. The outcome - again by means of level curve - is depicted in Figure 5. The strongest effect turns out to occur for the intermediate values of $\tau_{g}$, while it is much weaker for high and low values of the worst case tariff. The intrinsic logic is alike: for a given overhang the risk of the high tariff rate is covered by the binding overhang, while for low tariff rates the risk is minimal. Again, the value of the bound tariff and its reduction are most valuable to potential entrants (and hence generating most of the market access), when risk is higher. The diagonal line borders the non-effective region. Above the 
diagonal line, the bound rate is above the worst case tariff and therefore unable to generate market access. ${ }^{14}$

These simulations add some novel perspective on the empirical evidence presented in Figure 1: if political risk is a $\gamma$-type risk, the riskier countries (East of the scatter plot) benefit the most in terms of market access from bound rate negotiations, whilst, if the relevant political risk is of the $\tau_{g}$-type, the countries in the centered corridor take the greatest advantage from this type of policy. Still, the actual percentage values of the numerical simulation must be interpreted with caution. In primis, they are sensitive to the shape parameter of the Pareto distribution, as indicated in Table 2. In secundis, the value of the parameters used is not calibrated to real data. The advantage of this approach is that it allows us to arrive at model predictions concerning the market access of firms for different risk profiles, yet we are unable to generate insights on absolute trade volumes and other market openness measures.

Finally, we consider how entry into a market may differ in various economies, distinct by the initial capital required to start up the export activity $\left(F_{e}\right)$, the degree of competition $(\mu)$ on the market and the market size $(Z)$. We run the same type of policy experiment - a reduction of ten per cent in the bound rate for different levels of risk - and report in Table 2 the range of market access obtained. For comparison, the first row reports the results obtained for the benchmark case,

14 To be precise, a reduction of ten per cent of the bound rate on the diagonal line would bring the bound rate below $\tau_{g}$ to a binding level. However, the net reduction would be less than ten per cent, hardly comparable to the thought experiment proposed. Therefore, we decided to omit this case. 


\begin{tabular}{|l|c|l|l|}
\hline & Value & Simulation 1 & Simulation 2 \\
\hline & & $\gamma=0 \%-100 \%$ & $\tau_{g}=0 \%-250 \%$ \\
\hline \hline Benchmark Simulation: & & $0.18 \%-22.32 \%$ & $0 \%-9.69 \%$ \\
\hline \hline High Fixed Costs $\left(F_{e}\right):$ & 100 & $0.23 \%-24.74 \%$ & $0 \%-11.72 \%$ \\
Low Fixed Costs $\left(F_{e}\right):$ & 10 & $0.08 \%-14.26 \%$ & $0 \%-5.29 \%$ \\
\hline High Competition $(\mu):$ & 0.9 & $0.04 \%-9.09 \%$ & $0 \%-4.06 \%$ \\
Low Competition $(\mu):$ & 0.55 & $0.64 \%-40.67 \%$ & $0 \%-17.80 \%$ \\
\hline Big Country $(Z):$ & 8 & $0.10 \%-15.49 \%$ & $0 \%-5.89 \%$ \\
Small Country $(Z):$ & 1 & $0.23 \%-24.74 \%$ & $0 \%-11.27 \%$ \\
\hline High Shape Parameter $(a):$ & 0.4 & $0.15 \%-15.12 \%$ & $0 \%-7.12 \%$ \\
Low Shape Parameter $(a):$ & 0.1 & $0.25 \%-43.14 \%$ & $0 \%-15.29 \%$ \\
\hline
\end{tabular}

Table 2: Range of Market Access after a 10\% Reduction in the Bound Rate

The benchmark simulations refer to the results in figure 4 and 5 . The listed percentage range represents the minimum and maximum additional market access for the chosen parameter values after a $10 \%$ reduction in the bound rate. The parameter values of the benchmark simulations are listed in table 1. Each column represents a simulation in which with respect to the benchmark only the listed parameter is modified.

as illustrated above in Figures 4 and 5.

When fixed costs are low, the entry barrier is low and we can expect more firms to enter, for any level of the bound tariff. When it is high, a reduction in the expected tariff barrier can partially compensate for the high opportunity cost of entry. This is the intuition for an extensive margin which is potentially wider for an economy with a high fixed market access cost relative to one with a low fixed cost. Analogously, higher income countries and low degrees of competition on a market make entry more attractive to the potential foreign entrants. A reduction in the expected trade barrier is then needed in low-income countries or high competitive markets to partially offset these factors, explaining a wider range of market access at the extensive margin. 


\section{Conclusion}

Real world trade policy, as governed under WTO rules, deals at large with bound tariffs, besides applied tariffs. Economists have nominated the risk reduction reductions in the risk of changes in the destination markets' trade policy - as the main channel through which bound tariffs operate. Yet, by what mechanisms such risk reductions actually generate market access is largely unclear. In fact it is not at all obvious that a reduction in bound tariffs that remain above current applied and/or future applied tariff rates can generate additional trade. At the intensive margin, reductions in bound tariffs above applied rates have no price effect and hence cannot increase the export volume of already export-active firms. Accordingly, the effects of bound tariffs must be examined at the extensive margin of trade, i.e. via an increase in the number of exporters that chose to service a given destination market. These are effects where time and the timing of export market entry matter.

The present paper formalizes the underlying logic of firms' market entry decisions, risk and fixed export costs based on techniques known from the real options literature (e.g. Dixit, 1993). In doing so, we highlight the important role of bound tariffs at the extensive margin of trade. In our model, potential exporters to a given destination market can delay market entry and react to the risk reductions driven by bound tariffs. The central results of our analysis are that bound tariffs are more effective with higher risk destination markets, i.e. a large binding over- 
hang can command substantial market access for high risk countries. Furthermore, we show that reductions in bound tariffs do generate effective market access even when bound rates remain above current and long-term applied rates. 


\section{References}

Anderson, K. and Martin W. (2005). Scenarios for Global Trade Reform, World Bank, Washington, D.C.

Bchir, M. H., Jean, S. and Laborde, D. (2006). Binding Overhang and TariffCutting Formulas, Review of World Economics, 142, 2: 207-232.

Bernard, A., Eaton, J., Jensen, B. and Kortum, S. (2003). Plants and Productivity in International Trade. American Economic Review 93, 4: 1268-1290.

Bertola, G. (1998). Irreversible Investment. Research in Economics 52: 3-37.

Brander, J. A. and Spencer, B. (1984a). Trade Warfare: Tariffs and Cartels. Journal of International Economics 16: 227-242.

Brander, J. A. and Spencer, B. (1984b). Tariff Protection and Imperfect Competition. In Henryk Kierzkowski, ed. Monopolistic Competition and International Trade, Oxford: Oxford University Press. Reprinted as chapter 6 in Gene M. Grossman, 1992, Imperfect Competition and International Trade, Cambridge: MIT Press, 107-119.

Dixit, A. K. (1993). The art of smooth pasting. Chur, Switzerland: Harwood academic publishers. 
Dixit, A. K., and Pindyck, R. S. (1994). Investment Under Uncertainty. Princeton: Princeton University Press.

Evenett, S. (2007). Reciprocity and the Doha Round Impasse, Lessons for the Near-Term and After. Aussenwirtschaft (4).

Evenett, S. (2008). The Trade Policy Jungle: A Survival Guide for Academic Economists. The World Economy, 31, 4: 498-516.

Francois, J. F. (2001). Trade Policy Transparency and Investor Confidence: Some Implications for an Effective Trade Policy Review Mechanism. Review of International Economics, 9, 2: 303-316.

Francois, J. F. and Martin, W. (2004). Commercial Policy Variability, Bindings, and Market Access. European Economic Review 48: 665-679.

Hoekman, B. and Vines, D. (2007). Multilateral Trade Cooperation: What Next?, Oxford Review of Economic Policy, 23, 3: 311-334.

Jorgenson, D. (1963). Capital Theory and Investment Behavior. American Economic Review, 53: 247-259.

McDonald, R. and Siegel, D. R. (1986). The Value of Waiting to Invest. Quarterly Journal of Economics, 101, 4: 707-27. 
Melitz, M. J. (2003). The Impact of Trade on Intra-Industry Reallocations and Aggregate Industry Productivity. Econometrica, 71: 1695-1725.

Melitz, M. and Ottaviano, G. (2008). Market Size, Trade, and Productivity. Review of Economic Studies, 75, 1: 295-316.

Montagna, C. (2001). Efficiency Gaps, Love of Variety and International Trade. Economica, 68, 269: 27-44.

Pindyck, R. S. (1991). Irreversibility, Uncertainty, and Investment. Journal of Economic Literature, 29, 3: 1110-1148

Staiger, R. W. and Tabellini, G. (1987). Discretionary Trade Policy and Excessive Protection. American Economic Review 77, 5: 823-837.

Tybout, J. R., Das, M. and Roberts, M., (2007). Market Entry Costs, Producer Heterogeneity and Export Dynamics. Econometrica, 75: 837-873.

Van Wincoop, E. (1992). Terms of Trade Uncertainty, Savings, and the Production Structure, Journal of International Economics, 33: 305-325.

Walkenhorst, P. and Dihel, N. (2003), Tariff bindings, unused protection and agricultural trade iberalization, OECD Economic Studies, No. 36, 2003/1. 


\section{Appendix}

\section{A Countries Depicted in Figure 1}

Angola, Albania, United Arab Emirates, Argentina, Armenia, Australia, Austria, Belgium, Burkina Faso, Bangladesh, Bulgaria, Bahrain, Bolivia, Brazil, Brunei Darussalam, Botswana, Canada, Switzerland, Chile, China, Côte d'Ivoire, Cameroon, Congo, Colombia, Costa Rica, Cuba, Cyprus, Czech Republic, Germany, Denmark, Dominican Republic, Ecuador, Egypt, Spain, Estonia, Finland, France, Gabon, United Kingdom, Ghana, Guinea, Gambia, Guinea-Bissau, Greece, Guatemala, Guyana, Hong Kong, Honduras, Croatia, Haiti, Hungary, Indonesia, India, Ireland, Iceland, Israel, Italy, Jamaica, Jordan, Japan, Kenya, Korea, Kuwait, Sri Lanka, Lithuania, Luxembourg, Latvia, Morocco, Moldova, Rep.of, Madagascar, Mexico, Mali, Malta, Burma, Mongolia, Mozambique, Malawi, Malaysia, Namibia, Niger, Nigeria, Nicaragua, Netherlands, Norway, New Zealand, Oman, Pakistan, Peru, Philippines, Papua New Guinea, Poland, Portugal, Paraguay, Qatar, Romania, Saudi Arabia, Senegal, Singapore, Sierra Leone, El Salvador, Slovakia, Slovenia, Sweden, Togo, Thailand, Trinidad and Tobago, Tunisia, Turkey, Taiwan, Tanzania, United Rep. of, Uganda, Ukraine, Uruguay, United States of America, Venezuela, Vietnam, South Africa, Congo (Democratic Republic of the), Zambia, Zimbabwe

\section{B The $\left(1+\tau_{j}\right)^{-k}$ curve}

With reference to equation (14) let:

$$
\begin{aligned}
f(t) & =\left(1+\tau_{j}(t)\right)^{-k}=\left(1+b_{j} e^{-\alpha_{j} t}\right)^{-k} \\
\lim _{t \rightarrow \infty} f(t) & =1 \\
\lim _{t \rightarrow 0} f(t) & =\left(1+b_{j}\right)^{-k} \\
\frac{\partial f(t)}{\partial t} & =\frac{k \alpha_{j} b_{j}}{e^{\alpha_{j} t}\left(1+b_{j} e^{-\alpha_{j} T}\right)^{k+2}} \geq 0 \\
\frac{\partial^{2} f(t)}{\partial t^{2}} & =\frac{k \alpha_{j}^{2} b_{j}}{e^{\alpha_{j} t}\left(1+b_{j} e^{-\alpha_{j} t}\right)^{k+2}}\left[-1+\frac{b_{j}(k+2)}{e^{\alpha_{j} t}\left(1+b_{j} e^{-\alpha_{j} t}\right)}\right] \lesseqgtr 0
\end{aligned}
$$

Note that the sign of $\frac{\partial^{2} f(t)}{\partial t^{2}}$ depends on the term in the square bracket. We have:

$$
\begin{aligned}
\left.\frac{\partial^{2} f(t)}{\partial t^{2}}\right|_{T^{*}}=0 & \Leftrightarrow\left[-1+\frac{b_{j}(k+2)}{e^{\alpha_{j} T^{*}}\left(1+b_{j} e^{-\alpha_{j} T^{*}}\right)}\right]=0 \\
& \Leftrightarrow \quad \ln b_{j}+\ln (k+2)=\alpha_{j} T^{*}+\ln \left(1+b_{j} e^{-\alpha_{j} T^{*}}\right)
\end{aligned}
$$

and for $t>T^{*}, \frac{\partial^{2} f(t)}{\partial t^{2}}<0$, for $t<T^{*}, \frac{\partial^{2} f(t)}{\partial t^{2}}>0$. Therefore, $f(t)$ has a flex in $T^{*}$, it is concave for $t>T^{*}$, convex for $t<T^{*}$.

This proves that the curve $\pi\left(\tau_{j}(T)\right), j=l, g$ is S-shaped. 


\section{CESifo Working Paper Series}

for full list see www.cesifo-group.org/wp

(address: Poschingerstr. 5, 81679 Munich, Germany, office@cesifo.de)

2797 Margit Osterloh and Bruno S. Frey, Research Governance in Academia: Are there Alternatives to Academic Rankings?, September 2009

2798 Thiess Buettner and Clemens Fuest, The Role of the Corporate Income Tax as an Automatic Stabilizer, September 2009

2799 Annette Alstadsæter, Measuring the Consumption Value of Higher Education, September 2009

2800 Peter Friedrich, Chang Woon Nam and Janno Reiljan, Local Fiscal Equalization in Estonia: Is a Reform Necessary?, September 2009

2801 Evžen Kočenda and Jan Hanousek, State Ownership and Control in the Czech Republic, September 2009

2802 Michael Stimmelmayr, Wage Inequality in Germany: Disentangling Demand and Supply Effects, September 2009

2803 Biswa N. Bhattacharyay, Towards a Macroprudential Surveillance and Remedial Policy Formulation System for Monitoring Financial Crisis, September 2009

2804 Margarita Katsimi, Sarantis Kalyvitis and Thomas Moutos, "Unwarranted" Wage Changes and the Return on Capital, September 2009

2805 Christian Lessmann and Gunther Markwardt, Aid, Growth and Devolution, September 2009

2806 Bas Jacobs and Dirk Schindler, On the Desirability of Taxing Capital Income to Reduce Moral Hazard in Social Insurance, September 2009

2807 Hans Gersbach and Noemi Hummel, Climate Policy and Development, September 2009

2808 David E. Wildasin, Fiscal Competition for Imperfectly-Mobile Labor and Capital: A Comparative Dynamic Analysis, September 2009

2809 Johan Eyckmans and Cathrine Hagem, The European Union's Potential for Strategic Emissions Trading through Minimal Permit Sale Contracts, September 2009

2810 Ruediger Bachmann and Christian Bayer, The Cross-section of Firms over the Business Cycle: New Facts and a DSGE Exploration, October 2009

2811 Slobodan Djajić and Michael S. Michael, Temporary Migration Policies and Welfare of the Host and Source Countries: A Game-Theoretic Approach, October 2009 
2812 Devis Geron, Social Security Incidence under Uncertainty Assessing Italian Reforms, October 2009

2813 Max-Stephan Schulze and Nikolaus Wolf, Economic Nationalism and Economic Integration: The Austro-Hungarian Empire in the Late Nineteenth Century, October 2009

2814 Emilia Simeonova, Out of Sight, Out of Mind? The Impact of Natural Disasters on Pregnancy Outcomes, October 2009

2815 Dan Kovenock and Brian Roberson, Non-Partisan 'Get-Out-the-Vote' Efforts and Policy Outcomes, October 2009

2816 Sascha O. Becker, Erik Hornung and Ludger Woessmann, Catch Me If You Can: Education and Catch-up in the Industrial Revolution, October 2009

2817 Horst Raff and Nicolas Schmitt, Imports, Pass-Through, and the Structure of Retail Markets, October 2009

2818 Paul De Grauwe and Daniel Gros, A New Two-Pillar Strategy for the ECB, October 2009

2819 Guglielmo Maria Caporale, Thouraya Hadj Amor and Christophe Rault, International Financial Integration and Real Exchange Rate Long-Run Dynamics in Emerging Countries: Some Panel Evidence, October 2009

2820 Saša Žiković and Randall K. Filer, Hybrid Historical Simulation VaR and ES: Performance in Developed and Emerging Markets, October 2009

2821 Panu Poutvaara and Andreas Wagener, The Political Economy of Conscription, October 2009

2822 Steinar Holden and Åsa Rosén, Discrimination and Employment Protection, October 2009

2823 David G. Mayes, Banking Crisis Resolution Policy - Lessons from Recent Experience Which elements are needed for robust and efficient crisis resolution?, October 2009

2824 Christoph A. Schaltegger, Frank Somogyi and Jan-Egbert Sturm, Tax Competition and Income Sorting: Evidence from the Zurich Metropolitan Area, October 2009

2825 Natasa Bilkic, Thomas Gries and Margarethe Pilichowski, Stay in School or Start Working? - The Human Capital Investment Decision under Uncertainty and Irreversibility, October 2009

2826 Hartmut Egger and Udo Kreickemeier, Worker-Specific Effects of Globalisation, October 2009

2827 Alexander Fink and Thomas Stratmann, Institutionalized Bailouts and Fiscal Policy: The Consequences of Soft Budget Constraints, October 2009 
2828 Wolfgang Ochel and Anja Rohwer, Reduction of Employment Protection in Europe: A Comparative Fuzzy-Set Analysis, October 2009

2829 Rainald Borck and Martin Wimbersky, Political Economics of Higher Education Finance, October 2009

2830 Torfinn Harding and Frederick van der Ploeg, Is Norway's Bird-in-Hand Stabilization Fund Prudent Enough? Fiscal Reactions to Hydrocarbon Windfalls and Graying Populations, October 2009

2831 Klaus Wälde, Production Technologies in Stochastic Continuous Time Models, October 2009

2832 Biswa Bhattacharyay, Dennis Dlugosch, Benedikt Kolb, Kajal Lahiri, Irshat Mukhametov and Gernot Nerb, Early Warning System for Economic and Financial Risks in Kazakhstan, October 2009

2833 Jean-Claude Trichet, The ECB's Enhanced Credit Support, October 2009

2834 Hans Gersbach, Campaigns, Political Mobility, and Communication, October 2009

2835 Ansgar Belke, Gunther Schnabl and Holger Zemanek, Real Convergence, Capital Flows, and Competitiveness in Central and Eastern Europe, October 2009

2836 Bruno S. Frey, Simon Luechinger and Alois Stutzer, The Life Satisfaction Approach to Environmental Valuation, October 2009

2837 Christoph Böhringer and Knut Einar Rosendahl, Green Serves the Dirtiest: On the Interaction between Black and Green Quotas, October 2009

2838 Katarina Keller, Panu Poutvaara and Andreas Wagener, Does Military Draft Discourage Enrollment in Higher Education? Evidence from OECD Countries, October 2009

2839 Giovanni Cespa and Xavier Vives, Dynamic Trading and Asset Prices: Keynes vs. Hayek, October 2009

2840 Jan Boone and Jan C. van Ours, Why is there a Spike in the Job Finding Rate at Benefit Exhaustion?, October 2009

2841 Andreas Knabe, Steffen Rätzel and Stephan L. Thomsen, Right-Wing Extremism and the Well-Being of Immigrants, October 2009

2842 Andrea Weber and Christine Zulehner, Competition and Gender Prejudice: Are Discriminatory Employers Doomed to Fail?, November 2009

2843 Hadi Salehi Esfahani, Kamiar Mohaddes and M. Hashem Pesaran, Oil Exports and the Iranian Economy, November 2009

2844 Ruediger Bachmann and Christian Bayer, Firm-Specific Productivity Risk over the Business Cycle: Facts and Aggregate Implications, November 2009 
2845 Guglielmo Maria Caporale, Burcu Erdogan and Vladimir Kuzin, Testing for Convergence in Stock Markets: A Non-Linear Factor Approach, November 2009

2846 Michèle Belot and Jan Fidrmuc, Anthropometry of Love - Height and Gender Asymmetries in Interethnic Marriages, November 2009

2847 Volker Nitsch and Nikolaus Wolf, Tear Down this Wall: On the Persistence of Borders in Trade, November 2009

2848 Jan K. Brueckner and Stef Proost, Carve-Outs Under Airline Antitrust Immunity, November 2009

2849 Margarita Katsimi and Vassilis Sarantides, The Impact of Fiscal Policy on Profits, November 2009

2850 Scott Alan Carson, The Relationship between Stature and Insolation: Evidence from Soldiers and Prisoners, November 2009

2851 Horst Raff and Joachim Wagner, Intra-Industry Adjustment to Import Competition: Theory and Application to the German Clothing Industry, November 2009

2852 Erkki Koskela, Impacts of Labor Taxation with Perfectly and Imperfectly Competitive Labor Markets under Flexible Outsourcing, November 2009

2853 Cletus C. Coughlin and Dennis Novy, Is the International Border Effect Larger than the Domestic Border Effect? Evidence from U.S. Trade, November 2009

2854 Johannes Becker and Clemens Fuest, Source versus Residence Based Taxation with International Mergers and Acquisitions, November 2009

2855 Andreas Hoffmann and Gunther Schnabl, A Vicious Cycle of Manias, Crashes and Asymmetric Policy Responses - An Overinvestment View, November 2009

2856 Xavier Vives, Strategic Supply Function Competition with Private Information, November 2009

2857 M. Hashem Pesaran and Paolo Zaffaroni, Optimality and Diversifiability of Mean Variance and Arbitrage Pricing Portfolios, November 2009

2858 Davide Sala, Philipp J.H. Schröder and Erdal Yalcin, Market Access through Bound Tariffs, November 2009 